\title{
Erratum to: Full-dose Perindopril/Indapamide in the Treatment of Difficult-to-Control Hypertension: The FORTISSIMO Study
}

Yuri Aleksandrovich Karpov ${ }^{1}$ - On behalf of the FORTISSIMO physicians

Published online: 10 July 2017

(c) Springer International Publishing AG 2017

Erratum to: Clin Drug Investig 2017; 37:207-217

DOI 10.1007/s40261-016-0479-7

In the original version, the Page 211, Fig. 1, $Y$-axis was labelled incorrectly.

Below is the corrected version of Fig. 1.

The online version of the original article can be found under doi: 10.1007/s40261-016-0479-7.

Yuri Aleksandrovich Karpov

Yuri_Karpov@inbox.ru

1 Russian Cardiological Research and Production Complex,

3rd Cherepkovskaya st. 15A, Moscow 121552, Russia 


\section{a Overall patients $(n=1969)$}

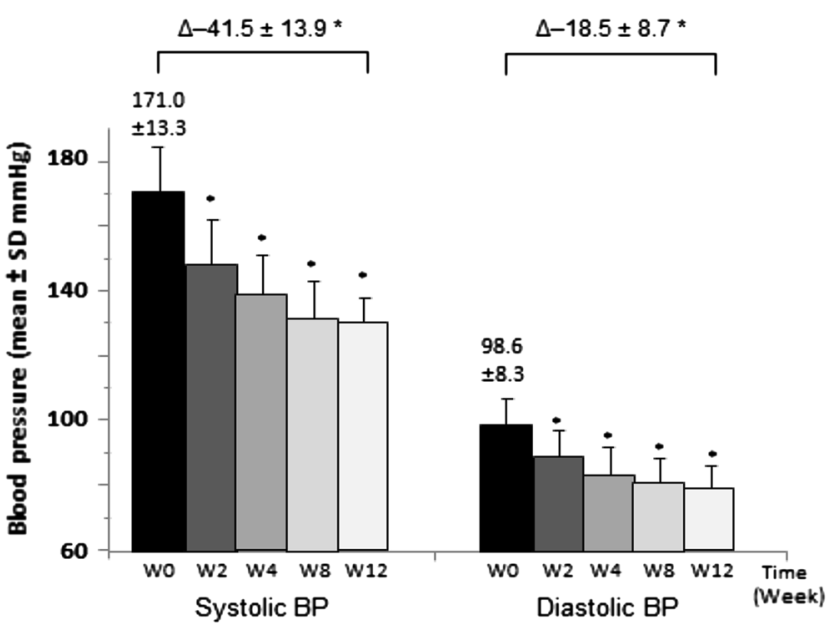

Fig. 1 Systolic and diastolic blood pressure reduction with single-pill combination perindopril/indapamide $10 / 2.5 \mathrm{mg}$ in patients with uncontrolled hypertension despite previous antihypertensive therapy.

\section{b Diabetic patients $(n=280)$}

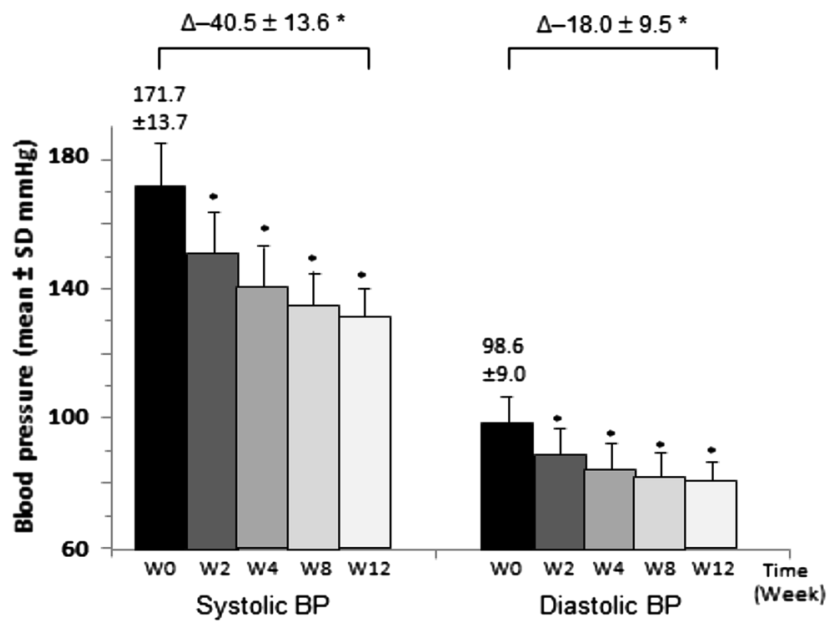

Results are presented for the overall population (a) and diabetic patients (b). $p<0.00001$ vs. previous visit 